\title{
The Department of Statistics \& Actuarial Science of the University of the Aegean is pleased to host the 3rd Conference in Actuarial Science and Finance, to be held on Samos, on September 2-5, 2004.
}

This event is jointly organized with the Katholieke Universiteit Leuven (Department of Applied Economics and Department of Mathematics), the Université Catholique de Louvain (Institute of Statistics and Actuarial research group) and the University of Copenhagen (Laboratory of Actuarial Mathematics).

The Conference allows the presentation of the latest works in the area of actuarial science and finance. It is open to all persons interested in actuarial science and finance, be they from universities, insurance companies, banks, consulting firms or regulatory authorities. The conference aims to facilitate the contact and the communication between the practicians and the researchers.

The topics of the sections include:

- Extremes and Large Deviations in Actuarial Science - Chair J. Teugels

- Non-life Insurance - Chair R. Verrall

- Advances in Incomplete Markets - Chair Th. Zariphopoulou

- Modelling Dependence in Actuarial Science - Chair Th. Mikosch

- Risk and Control - Chair S. Asmussen

- Life, Pension and Health Insurance - Chair H. Gerber

There will be four short courses. Two before the conference: 30th of August 1 st of September

- Stochastic Claims Reserving, by R.J. Verrall

- Stochastic Control Applied to Actuarial Problems, by H. Schmidli

and the other two after the conference: 6th September - 8th September

- Risk Measures and Optimal Portfolio Selection (with applications to elliptical distributions), by J. Dhaene and E. Valdez

- Advanced Statistical Methods for Insurance, by M. Denuit

Postgraduate students and young reseachers are specially welcome.

\section{Scientific Committee:}

Asmussen Soeren

Denuit Michel

Foss Serguei 
Frangos Nicos

Gerber Hans

Goovaerts Marc

Guillen Montserrat

Konstantinides Dimitrios

Makov Udi

Marceau Etienne

Mikosch Thomas

$\mathrm{Ng}$ Kai

Papaioanou Takis (Chair)

Tessaromatis Nicos

Teugels Jef

Verrall Richard

Willder Mark

Zariphopoulou Thaleia

\section{Organizing Committee:}

Dhaene Jan

Frangos Nicos (Chair)

Konstantinides Dimitrios

Mikosch Thomas

Purcaru Oana

Schmidli Hanspeter

Teugels Jef

Walhin Jean-Francois

\section{Local Committee:}

Chatzispyros Spyridon

Giannakopoylos Athanasios

Katsis Athanasios

Konstantinides Dimitrios (Chair)

Milionis Alexandros

Nakas Christos

Poufinas Thomas

For further information, please refer to

http://www.stat.ucl.ac.be/Samos2004/ 